\title{
AVALIAÇÃO GOVERNAMENTAL DOS RESULTADOS DA LEI DO BEM
}

\section{GOVERNMENTAL EVALUATION OF THE RESULTS OF THE GOOD LAW}

\author{
Juliana Aparecida Rocha Cunha \\ Centro Universitário UNA - Belo Horizonte - MG \\ juliana_rocha18@hotmail.com \\ Poueri do Carmo Mário \\ Centro Universitário UNA / UFMG \\ poueri@gmail.com
}

Submissão: 04/12/2018

Aprovação: $18 / 12 / 2018$

Artigo Aprovado no Fast Track no EGEN de 2018 em convênio com a revista E\&G

\begin{abstract}
RESUMO
Este artigo verificou a forma que o Ministério da Ciência, Tecnologia, Inovações e Comunicações (MCTIC) avalia os retornos dos incentivos concedidos pela Lei 11.196/2005, conhecida como a Lei do Bem. O objetivo deste incentivo é promover o efeito alavancagem do setor econômico industrial nacional, aumentando a competitividade no cenário mundial, por meio de estímulo aos investimentos em P\&D (pesquisa e desenvolvimento) através de inventivos fiscais em que o gasto público é capaz de ampliar o gasto privado em inovação (MCTIC/ SETEC, 2015). O estudo baseou-se nos relatórios publicados pelo MCTIC com as informações anuais sobre a Lei do Bem dos anos-base 2006 até 2014. Observou-se uma grande preocupação do Ministério em ter um aumento nos investimentos em $\mathrm{P} \& \mathrm{D}$, mas não em verificar se houve um efetivo desenvolvimento tecnológico. É necessário que os órgãos competentes tenham controles dos efetivos retornos dos incentivos que justifiquem as renúncias de receitas realizadas pelo governo e que estas informações estejam disponibilizadas de forma clara e coerente para a sociedade.
\end{abstract}

Palavras-chave: Lei do Bem; incentivo fiscal; MCTIC.

\begin{abstract}
This article verified how the Ministry of Science, Technology, Innovation and Communications (MCTIC) evaluates the returns of the incentives granted by Law $11,196 / 2005$, known as the Good Law. The objective of this incentive is to promote the leverage effect of the economic sector $(R \& D)$, by increasing competitiveness on the world stage, by stimulating R\&D investments through taxes incentives in which public spending can increase private spending on innovation (MCTIC/ SETEC, 2015). The study was based on the reports published by MCTIC with the annual information on the Good Law of the base years 2006 to 2014. There was a great concern of the Ministry to have an increase in investments in
\end{abstract}


$\mathrm{R} \& \mathrm{D}$, but not to verify if there was effective technological development. It is necessary that the pertinent authorities have controls of the effective returns of the incentives that justify the renunciations of revenues realized by the government and that this information is made available in a clear and coherent way for the society.

Keywords: Good Law; Tax Incentive; MCTIC

\section{Introdução}

O tema inovação tecnológica vem ocupando lugar de destaque na agenda econômica de diversos países. Considerada como a mola propulsora para o desenvolvimento socioeconômico, a inovação vem sendo um diferencial para a sobrevivência das empresas no mundo globalizado, tornando os países mais competitivos e com possibilidades de melhorias na qualidade de vida da população. (HOLANDA; PIRES, 2015; VIEIRA et al., 2015; ZITTEI et al., 2016).

Dentre as ferramentas que podem ser utilizadas pelo governo para estímulo à inovação, temse os incentivos fiscais que são utilizados para interferir na quantidade e qualidade das atividades de inovação. Existem vários mecanismos de incentivo: deduções, amortizações, depreciações ou crédito fiscal. Estas políticas buscam estimular os gastos das empresas com a atividade de inovação (CALZOLAIO; DATHEIN, 2012).

Os incentivos fiscais são usados em diversos países e com variados propósitos, dentre eles o estímulo às atividades de inovação nas empresas e atração de investimentos para esta área. Outros propósitos que podem ser destacados são a motivação da mudança de comportamento da população, estimulando-a à troca de equipamentos como refrigeradores, máquinas de lavar louças e roupas por equipamentos com sistemas elétricos mais eficientes, ou à troca da frota de veículos por carros elétricos (GALARRAGA; ABADIE; KALLBEKKEN, 2016; RUMINA; BALANDINA; BANNOVA, 2015).

Devido à importância das políticas públicas de estímulo à inovação torna-se importante a avaliação do governo da eficiência das políticas implementadas, verificando se estas atendem os objetivos pretendidos.

O problema investigado neste trabalho relaciona-se com a forma que o MCTIC avalia os retornos dos incentivos concedidos no capítulo III da Lei 11.196/2005, também conhecida como Lei do Bem. A referida lei tem como objetivo promover o efeito alavancagem do setor econômico industrial nacional, aumentando a competitividade no cenário mundial, por meio de estímulo aos investimentos em P\&D (pesquisa e desenvolvimento) através de inventivos fiscais em que o gasto público é capaz de ampliar o gasto privado em inovação (MCTIC/ SETEC, 2015).

Assim, o objetivo principal deste artigo é analisar a forma que o MCTIC avalia o retorno dos incentivos fiscais concedidos pela Lei do Bem com base nas informações contidas nos relatórios anuais publicados pelo referido Ministério. Já o objetivo específico é verificar se o método adotado pelo MCTIC de avaliar o retorno dos incentivos fiscais é eficiente, ou seja, consegue verdadeiramente avaliar se esta política pública alcança os objetivos esperados.

Rumina et al.(2015) afirmaram que a necessidade de avaliar a eficácia dos incentivos fiscais, que visam motivar desenvolvimento inovativo, decorre da falta de uma base teórica consistente e da baixa eficácia de tais benefícios na prática. Sem uma avaliação detalhada da eficácia dos incentivos fiscais, a retirada assistemática de alguns benefícios e a inclusão de outros que muitas vezes não são eficazes acontecerá.

Foi realizado ainda, pelos autores, um estudo bibliométrico a fim de conhecer as publicações sobre o tema. A bibliometria segundo Araújo (2006) é a análise quantitativa da informação, 
consistindo na aplicação de técnicas estatísticas e matemáticas para medição dos índices de produção e de disseminação do conhecimento científico.

Utilizou-se o portal da Capes para realizar este levantamento. Buscou-se o assunto "Lei do Bem", sendo encontrados 67 trabalhos. Excluindo-se os artigos repetidos, apurou-se 60 artigos. Nenhum destes trabalhos analisa a metodologia do MCTIC de avaliar os retornos da Lei do Bem, o que demonstra a originalidade e relevância deste estudo.

\section{Inovação tecnológica}

O conceito de inovação está ligado a implementação de um produto, que pode ser um bem ou um serviço novo ou ter modificações significativas. Inclui-se também a introdução de "um processo ou um novo método de marketing, ou um novo método organizacional nas práticas de negócios, na organização do local de trabalho ou nas relações externas" (OECD, 2004, p. 55).

Pode-se afirmar ainda que o conceito de inovação relaciona-se à noção de tecnologia, podendo ser sintetizada como "conhecimento técnico associado à produção de bens e serviços" (CONCEIÇÃO, 2000, p. 60). Neste sentido, pode-se conceituar a inovação como "novos e aprimorados produtos e processos, novas formas organizacionais, aplicação da tecnologia existente em novos campos, descoberta de novos recursos e abertura de novos mercados" (NIOSI et al., 1993, p. 209, tradução nossa). As inovações são as principais forças para gerar desenvolvimento econômico de uma região ou país (SCHUMPETER, 1997).

A inovação abordada neste trabalho é a inovação tecnológica, visto que este o termo utilizado na Lei do Bem, que a conceitua como a criação de novos produtos ou processos de fabricação, bem como a incorporação de "novas funcionalidades ou características ao produto ou processo que gerem melhorias incrementais e efetivo ganho de qualidade ou produtividade, resultando maior competitividade no mercado" (BRASIL, 2006).

A inovação tecnológica no manual de Frascati (2013, p. 23) é qualquer "conjunto de diligências científicas, tecnológicas, organizacionais, financeiras e comerciais, incluindo o investimento em novos conhecimentos, que realizam ou destinam-se a levar à realização de produtos e processos tecnologicamente novos e melhores", estando ligada ao desenvolvimento econômico e ao crescimento da produtividade de forma positiva. Ela é essencial ao desenvolvimento econômico e social, sendo estimulada em diversos países através de políticas de apoio, dentre elas os incentivos fiscais (ZUCOLOTO, 2010).

\section{$3 \quad$ Políticas públicas de incentivo à inovação tecnológica}

Para Secchi (2013, p. 2), "uma política pública é uma diretriz elaborada para enfrentar um problema público". Ela toma forma de programas públicos, projetos, leis, inovações tecnológicas e organizacionais, subsídios governamentais, dentre outros. Pode-se citar, como exemplos de operacionalização de políticas públicas, as intervenções na economia e leis de incentivo à inovação e capacitação tecnológica. As políticas públicas podem ser também analisadas por meio de esquemas analíticos (tipologias).

O Estado tem um papel importante no estímulo à inovação, coordenando e direcionando o progresso tecnológico do país, influenciando o comportamento, as estratégias e as decisões das empresas no que diz respeito às suas atividades inovativas. A relação entre investimentos em $\mathrm{P} \& \mathrm{D}$, avanço tecnológico e crescimento econômico é fundamental para as políticas de incentivo à inovação (AUDRETSCH et al., 2002; ARCHILA, 2015)

Muitos governos concedem incentivos fiscais para reduzir o custo de P\&D no intuito de estimular a inovação. De acordo com Audretsch et al. (2002) a atividade de pesquisa e desenvolvimento é o principal recurso utilizado pelas empresas para identificar a resposta empresarial às condições competitivas do mercado e às direções estratégicas da firma. Porém 
as empresas dependem em graus distintos da atividade em P\&D: empresas maiores em ambientes competitivos normalmente dependem mais que empresas menores que usam fontes externas de conhecimentos técnicos. A dificuldade das empresas em conseguir financiamentos para os projetos de P\&D é um dos motivos frequentemente citados para justificar a existência de tais programas de governo, que muitas vezes envolvem orçamentos substanciais. A eficácia de programas de incentivo fiscais para $\mathrm{P} \& \mathrm{D}$, no entanto, continua a ser o objeto de intenso debate entre os economistas (ARAÚJO, 2010; LOKSHIN; MOHNEN, 2012)

Chiang et al. (2012) relata que em muitos países os investimentos em P\&D são insignificantes em relação ao PIB (Produto Interno Bruto), sendo alguns dos fatores a má concepção de incentivos fiscais pelos governos e o baixo compromisso do governo com as indústrias. Ele ressalta a importância de incentivos fiscais para motivar as empresas a investirem em P\&D.

\section{$4 \quad$ Incentivo fiscal}

Pode-se definir incentivos fiscais como "renúncias de receitas públicas que beneficiam os contribuintes" (FORMIGONI, 2008, p. 25). Ao fazer uso desta ferramenta, o governo visa estimular determinadas áreas, não privilegiando o contribuinte, mas utilizando-o como um agente de um benefício em que a sociedade é também beneficiária (ZITTEI et al., 2016). Almeida (2000) corrobora desta ideia afirmando que a renúncia fiscal é a utilização de um tributo com finalidade extrafiscal, visando atingir objetivos econômicos, sociais ou políticoadministrativos, tais como incentivar o desenvolvimento de determinadas regiões ou segmentos econômicos estratégicos e estimular o comportamento do contribuinte. Formigoni (2008) acrescenta que os incentivos fiscais são instrumentos de estímulo ao desenvolvimento e de melhoria da qualidade de vida da população, ou seja, o incentivo precisa gerar um retorno vinculado à promoção do bem comum; caso não ocorra, será um benefício físcal que gera vantagens somente para o contribuinte. $\mathrm{O}$ autor ainda afirma que os incentivos podem ser concedidos na forma de isenções, reduções de alíquota e de base de cálculo do tributo, alíquota zero, subvenções, créditos presumidos, subsídios e diferimento.

Neste contexto, conforme a Lei Complementar 101/2000 (Lei de Responsabilidade Fiscal), a renúncia compreende "anistia, remissão, subsídio, crédito presumido, concessão de isenção em caráter não geral, alteração de alíquota ou modificação de base de cálculo que implique redução discriminada de tributos ou contribuições, e outros benefícios que correspondam a tratamento diferenciado" (BRASIL, 2004).

Chiang et al. (2012) apontam como vantagens dos incentivos fiscais a facilidade de gerenciar e avaliar os recursos, o fato de eles não fazerem distinção de tipo de empresa, setor ou região, a baixa susceptibilidade à corrupção política do que outras ferramentas como subsídios, não gerarem desembolsos e atraírem menos oposição em relação a outras ferramentas para estimular o crescimento. Rumina et al. (2015) destacam como desvantagens a dificuldade em avaliar a eficácia e a eficiência desta ferramenta após a sua implementação, os altos gastos iniciais, no caso de atividades inovadoras, e o longo tempo para se obter o retorno do investimento.

Segundo Almeida (2000), os dispositivos especiais à regra tributária visam beneficiar grupos relativamente restritos de contribuintes, concedendo benefícios tributários, sendo o incentivo fiscal um subconjunto dos benefícios tributários. Para ser enquadrado como incentivo fiscal, é necessário que ele seja um "indutor de comportamento", ou seja, que estimule agentes a agir de determinada forma, visando atingir uma meta econômica ou social previamente definida. Como exemplo tem-se a Lei 11.196/2005, a Lei do Bem, que concede incentivos para estimular os investimentos das empresas em pesquisa e desenvolvimento, registro de patentes, compras de bens de capital e contratação de pesquisadores, visando ao desenvolvimento tecnológico e econômico do país. 


\subsection{Contexto das políticas de incentivo à inovação tecnológica no Brasil}

Viotti (2008) divide a história da política de inovação no Brasil em três partes: a primeira compreende o período de 1950 a 1980 (desenvolvimento pelo crescimento), a segunda corresponde às duas últimas décadas do século XX (desenvolvimento pela eficiência), e a última inicia em 2000 e ainda está em andamento (desenvolvimento pela inovação).

A primeira parte caracteriza-se pela industrialização de substituição de importações, o protecionismo à indústria nacional que estava nascendo, o apoio aos investimentos privados nacionais e estrangeiros e criação de empresas públicas em setores estratégicos para o desenvolvimento nacional. Acreditava-se que a indústria desenvolvida para substituir as importações seria o caminho para acessar as tecnologias. O conhecimento desenvolvido nas universidades e centros de pesquisa, de acordo com as diretrizes governamentais, seria aplicado no setor produtivo. Podem-se citar como exemplo as pesquisas relacionadas a semicondutores no Brasil que se iniciaram com a criação do Laboratório de Microeletrônica da Universidade de São Paulo (USP) e do Laboratório de Eletrônica e Dispositivos (LED) da Universidade Estadual de Campinas (UNICAMP) (ARAÚJO, 2012; FILIPPIN, 2016; MELO; RIOS; GUTIERREZ, 2001; VIOTTI, 2008). Embora o crescimento econômico tenha sido forte nestas três décadas, o país não teve o desenvolvimento tecnológico endógeno (produzido pelo país) para substituir as importações de tecnologia. Cabe ressaltar que este desenvolvimento foi comprometido pelas crises macroeconômicas e fiscais que comprometeram a capacidade do Estado de implementar novas políticas de desenvolvimento em Ciência e Tecnologia (C\&T) (VIOTTI, 2008).

A segunda fase é marcada pela liberação progressiva da economia, ou seja, o fim do protecionismo às indústrias nacionais e aumento da competitividade decorrente desta liberação. Viotti (2008) afirma que estas políticas protecionistas foram responsáveis pelos níveis de ineficiência da indústria e pelo persistente atraso econômico e tecnológico do Brasil. Outros pontos que marcam este período são as privatizações e a reforma econômica. Porém, observa-se novamente que o desenvolvimento é comprometido por uma crise fiscal, que reduziu drasticamente os investimentos federais em $\mathrm{P} \& \mathrm{D}$. Um ponto positivo desta fase foi a criação dos fundos setoriais, que receberiam contribuições específicas para financiar P\&D em 14 setores estratégicos, além de dois fundos especiais que promoveriam a interação universidade-empresa e a melhoria da infraestrutura de pesquisa nas universidades e centros de pesquisa, respectivamente. Desta forma boa parte do financiamento à $P \& D$ não estaria mais sujeita a cortes orçamentários (VIOTTI, 2008).

Por fim, na terceira fase o governo tem promovido iniciativas ao desenvolvimento tecnológico através dos programas (VIOTTI, 2008). Dentre eles pode-se mencionar o Centro de Excelência em Tecnologia Eletrônica Avançada (CEITEC) em empresa pública federal que foi criado através da doação da Motorola Semicondutores de uma linha de produção de circuitos integrados usada para o Brasil (FILIPPIN, 2016). Outras iniciativas que merecem destaque são a publicação da Lei da Inovação Tecnológica (Lei 10.973/2004), que dispõe sobre os "incentivos à inovação e à pesquisa científica e tecnológica no ambiente produtivo, com vistas à capacitação tecnológica, ao alcance da autonomia tecnológica e ao desenvolvimento do sistema produtivo nacional e regional do país"(BRASIL, 2004), a Lei do Bem publicada em 2005 que será detalhada no tópico a seguir e o Programa de Apoio ao Desenvolvimento Tecnológico da Indústria de Semicondutores (PADIS) vigente desde 2007, que concede a desoneração dos tributos federais que incidem no momento da implantação industrial, da produção e da comercialização dos produtos beneficiados. Para usufruir do PADIS as empresas ficam obrigadas a investirem em P\&D os valores estipulados na legislação (MDIC, 2017).

Outros incentivos que completam esta lista seriam os recursos financeiros ofertados pela FINEP e pelo BNDES e a manutenção do PPB (Processo Produtivo Básico) que surgiu em 
1991 com a publicação da Lei 8.387/1991. Ele é definido como um conjunto mínimo de operações que as fábricas precisam cumprir para fazer jus ao incentivo fiscal estabelecido na lei (redução da alíquota de IPI) (MDIC, 2017).

\subsubsection{Lei do Bem}

De acordo com Prata (2017) a Lei 11.196/2005, conhecida como Lei do Bem, é a principal ferramenta de estímulo às atividades de $\mathrm{P} \& \mathrm{D}$ e inovação nas empresas brasileiras, abrangendo todos os setores da economia. Para o autor, ela é "fundamental para sustentar o desenvolvimento da capacidade técnico-produtiva e o aumento do valor agregado da produção de bens e serviços"(PRATA, 2017, p. 10). A Lei do Bem concede incentivos fiscais às atividades de pesquisa tecnológica e desenvolvimento de inovação tecnológica para as empresas enquadradas nos regimes de tributação de lucro real e presumido, procurando estimular a inovação nas empresas e, dessa forma, contribuir para o crescimento do país. Ressalta-se que as empresas tributadas pelo lucro presumido fazem jus apenas ao incentivo relativo ao imposto sobre produto industrializado (IPI) (LOPES; BEUREN, 2016).

Os incentivos fiscais concedidos pela Lei do Bem podem ser definidos, resumidamente conforme Quadro 1.

Quadro 1 - Incentivos fiscais da Lei do Bem

\begin{tabular}{|c|c|c|c|}
\hline Benefício & Detalhamento & Gasto & Recuperação \\
\hline $\begin{array}{l}\text { Exclusão Adicional } \\
\quad 60 \% \text { a } 100 \%\end{array}$ & $\begin{array}{l}\text { Exclusão do Lucro Real e da base da CSLL dos } \\
\text { dispêndios com atividades de inovação }\end{array}$ & $\begin{array}{c}\text { Despesas } \\
\text { operacionais }\end{array}$ & $20,4 \%$ a $34 \%$ \\
\hline $\begin{array}{l}\text { Exclusão adicional } \\
\quad 50 \% \text { a } 250 \%\end{array}$ & $\begin{array}{l}\text { Exclusão do Lucro Real e da base da CSLL dos } \\
\text { dispêndios com atividades de inovação a serem } \\
\text { executadas por ICT's }\end{array}$ & Serviços de ICT & $10 \%$ a $51 \%$ \\
\hline Redução do IPI & $\begin{array}{l}\text { Redução de } 50 \% \text { incidente sobre máquinas e } \\
\text { equipamentos utilizados para P\&D }\end{array}$ & $\begin{array}{l}\text { Máquinas e } \\
\text { equipamentos } \\
\text { para P\&D }\end{array}$ & $50 \%$ \\
\hline $\begin{array}{c}\text { Depreciação } \\
\text { acelerada Integral }\end{array}$ & $\begin{array}{l}\text { Depreciação acelerada integral no próprio período da } \\
\text { aquisição de máquinas e equipamentos utilizados } \\
\text { para P\&D }\end{array}$ & $\begin{array}{l}\text { Máquinas e } \\
\text { equipamentos } \\
\text { para P\&D }\end{array}$ & $\begin{array}{l}\text { Benefício } \\
\text { financeiro }\end{array}$ \\
\hline $\begin{array}{l}\text { Amortização } \\
\text { Acelerada }\end{array}$ & $\begin{array}{l}\text { Amortização acelerada no próprio período da } \\
\text { aquisição de bens intangíveis utilizados para P\&D }\end{array}$ & $\begin{array}{l}\text { Bens intangíveis } \\
\text { para } P \& D\end{array}$ & $\begin{array}{l}\text { Benefício } \\
\text { financeiro }\end{array}$ \\
\hline $\begin{array}{l}\text { Redução a zero do } \\
\text { IRRF }\end{array}$ & $\begin{array}{l}\text { Redução a zero do IRRF incidente sobre remessas ao } \\
\text { exterior para manutenção de marcas e patentes }\end{array}$ & $\begin{array}{c}\text { Remessas para } \\
\text { manutenção de } \\
\text { marcas e patentes }\end{array}$ & $100 \%$ \\
\hline
\end{tabular}

Fonte: Inventta (2016)

Em relação à exclusão adicional das despesas operacionais, ressalta-se que as empresas beneficiadas podem excluir além dos $60 \%$ da soma dos dispêndios classificados como despesas operacionais pela legislação do IRPJ realizados com P\&D, $20 \%$ no caso de incremento da média do número de pesquisadores com dedicação exclusiva à pesquisa $\mathrm{e}$ desenvolvimento, contratados no ano-base e que seja superior a 5\% com referência ao ano anterior. Caso o valor seja inferior a 5\%, o valor acrescido será de $10 \%$. Pode-se também deduzir mais $20 \%$ do total dos gastos vinculados à pesquisa tecnológica e ao desenvolvimento de inovação tecnológica objeto de marca, patente concedida ou cultivar registrado (MCTIC/ SETEC, 2015).

Com relação à depreciação e amortização, há a possibilidade de o saldo não depreciado ou não amortizado ser excluído na determinação do lucro real no período em que for concluída a sua utilização.

O número de empresas que declararam ter usufruído dos incentivos fiscais (empresas participantes) e das empresas recomendadas (aquelas que atenderam as exigências da Lei do Bem para usufruir dos incentivos) vem crescendo ano após ano. A Lei do Bem iniciou em 
2006 com 130 empresas participantes e recomendadas e, no último relatório publicado pelo MCTIC em 2014, apresentou 1206 empresas participantes e 1008 empresas recomendadas. Para o MCTIC (2015, p. 12) este crescimento é "um indicador importante para assegurar o relativo sucesso dos investimentos privados" em P\&D. Contudo, verifica-se que somente 19 delas aparecem desde 2006, ano do início da vigência da Lei 11.196/2005.

Marques e Leal (2016) ressaltam que a Lei do Bem acabou com a obrigatoriedade que existia na legislação anterior de solicitar aprovação ao MCTIC para usufruir de incentivos fiscais desta natureza. Outro ponto destacado pelos autores é que a referida lei não exige que os investimentos sejam em relação às demandas do mercado, estimulando a etapa do processo de maior insegurança quanto à obtenção de resultados econômicos e financeiros.

Os incentivos incidem somente no segmento de maior risco tecnológico, onde ocorrem a pesquisa básica dirigida, a pesquisa aplicada e o desenvolvimento experimental (até a fase de desenvolvimento de protótipo), além da Tecnologia Industrial Básica e os serviços de apoio técnico diretamente ligados à P\&D das empresas conforme definidos no Decreto 5.798/2006. Não há a obrigatoriedade das atividades de $\mathrm{P} \& \mathrm{D}$ estarem ligadas à atividade fim da empresa, bastando que sejam classificadas como no Decreto $n^{\circ}$ 5.798/2006 (MCTIC, 2017).

\section{$5 \quad$ Metodologia}

A pesquisa é de suma importância para o conhecimento da realidade. Para (GODOY, 1995, p. 58) a pesquisa é "um esforço cuidadoso para a descoberta de novas informações ou relações e para a verificação e ampliação do conhecimento existente". Através dela pode-se responder aos inúmeros questionamentos que nos cercam. Ela é o caminho a ser seguido para alcançar as respostas, obedecendo a princípios, normas e técnicas (SANTOS, 2012).

No intuito de analisar a forma que o MCTIC avalia se os incentivos fiscais concedidos pela Lei do Bem e verificar se o MCTIC consegue verdadeiramente avaliar se esta política pública atende o objetivo para o qual foi instituída, utilizou-se a pesquisa quantitativa. Segundo (GODOY, 1995, p. 58) a pesquisa quantitativa é aquela em que o pesquisador conduz o seu trabalho a partir de um plano inicialmente estabelecido, "com hipóteses claramente especificadas e variáveis operacionalmente definidas". Quanto aos fins, a pesquisa classificase como explicativa, uma vez que será apresentado os resultados da análise dos relatórios divulgados pelo MCTIC sobre a Lei do Bem assim como esclarecer se o método de avaliação adotado pelo Ministério consegue avaliar a eficiência dos incentivos concedidos no desenvolvimento tecnológico do Brasil. Para Santos (2012) este tipo de pesquisa procura esclarecer a ocorrência de um fato aprofundando o saber sobre esta realidade.

Por fim, quanto aos meios, a pesquisa enquadra-se como bibliográfica e documental, consultando os dados no portal do MCTIC. Santos (2012), afirma que a pesquisa bibliográfica é feita com base em documentos existentes já elaborados, tais como livros, dicionários, jornais, revistas, dentre outros e que pesquisa documental é aquela realizada com base em documentos que não receberam tratamento de análise e síntese.

\section{Modelo de avaliação governamental da Lei do Bem}

O MCTIC iniciou em dezembro de 2007 a publicação de um relatório anual da utilização dos incentivos fiscais da Lei do Bem. No site, o Ministério disponibilizou os relatórios dos exercícios fiscais de 2006 a 2014. Os dados das empresas incentivadas são coletados pelo MCTIC por meio do formulário de preenchimento e envio obrigatório para o Ministério pelas empresas optantes da Lei do Bem.

Nos relatórios os resultados são consolidados por setores industriais, por região e por unidade da Federação. São apresentados os registros dos investimentos realizados em P\&D, a geração de renúncia fiscal, os dados sobre o comportamento dos investimentos realizados em P\&D 
numa série histórica dos últimos anos e outras informações a respeito dos investimentos em P\&D em relação ao PIB no Brasil. Consta ainda no referido relatório a listagem das empresas beneficiárias da Lei 11.196/2005. O último relatório disponibilizado pelo ministério é o do ano base 2014. Não foram disponibilizadas ainda as informações dos anos de 2015 a 2017.

Tabela 1 - Distribuição das empresas recomendadas por setores industriais

\begin{tabular}{l|r|r|r|r|r|r|r|r|r}
\hline \multirow{2}{*}{ SETORES } & \multicolumn{7}{c}{$\mathbf{N}^{\mathbf{0}}$ DE EMPRESAS RECOMENDADAS } \\
\cline { 2 - 10 } & $\mathbf{2 0 0 6}$ & $\mathbf{2 0 0 7}$ & $\mathbf{2 0 0 8}$ & $\mathbf{2 0 0 9}$ & $\mathbf{2 0 1 0}$ & $\mathbf{2 0 1 1}$ & $\mathbf{2 0 1 2}$ & $\mathbf{2 0 1 3}$ & $\mathbf{2 0 1 4}$ \\
\hline Agroindústria & 0 & 14 & 23 & 20 & 10 & 13 & 11 & 13 & 15 \\
Alimentos & 4 & 14 & 33 & 40 & 46 & 57 & 67 & 71 & 74 \\
Bens de Consumo & 2 & 21 & 33 & 37 & 46 & 52 & 49 & 59 & 43 \\
Construção Civil & 3 & 7 & 17 & 17 & 7 & 13 & 11 & 16 & 18 \\
Eletroeletrônica & 13 & 45 & 66 & 53 & 42 & 65 & 57 & 72 & 86 \\
Farmacêutica & 11 & 13 & 16 & 31 & 37 & 37 & 42 & 39 & 44 \\
Mecânica e Transportes & 30 & 81 & 114 & 111 & 147 & 154 & 125 & 189 & 190 \\
Metalurgia & 22 & 26 & 32 & 43 & 45 & 43 & 47 & 43 & 39 \\
Mineração & 2 & 1 & 1 & 4 & 7 & 13 & 18 & 19 & 17 \\
Moveleira & 0 & 8 & 11 & 14 & 8 & 21 & 22 & 15 & 5 \\
Outras Indústrias & 11 & 29 & 32 & 44 & 104 & 146 & 150 & 203 & 215 \\
Papel e Celulose & 5 & 7 & 7 & 12 & 13 & 14 & 17 & 17 & 19 \\
Química/ Petroquímica & 22 & 26 & 32 & 55 & 67 & 70 & 99 & 97 & 81 \\
Software & 4 & 1 & 20 & 31 & 45 & 57 & 65 & 98 & 145 \\
Telecomunicação & 0 & 3 & 17 & 21 & 6 & 2 & 1 & 9 & 12 \\
Têxtil & 1 & 4 & 6 & 9 & 9 & 10 & 6 & 17 & 5 \\
Total das empresas & $\mathbf{1 3 0}$ & $\mathbf{3 0 0}$ & $\mathbf{4 6 0}$ & $\mathbf{5 4 2}$ & $\mathbf{6 3 9}$ & $\mathbf{7 6 7}$ & $\mathbf{7 8 7}$ & $\mathbf{9 7 7}$ & $\mathbf{1 0 0 8}$ \\
\hline
\end{tabular}

Fonte: Elaborado pelos autores com base em informações do MCTIC (2018)

As empresas recomendadas (aquelas que atenderam as exigências da Lei do bem para usufruir dos incentivos) são agrupadas em 16 (dezesseis) setores, tendo por base a Classificação Nacional de Atividades Econômicas (CNAE), utilizando-se os 2 (dois) primeiros dígitos do código para tal classificação, informados pelas empresas no FORMP\&D. Analisando as empresas recomendadas por setores de atividade observa-se que o setor de mecânica foi o que teve, em todos os anos, o maior número de empresas recomendadas. De acordo com Castro et al. (2014) este investimento diferenciado das empresas deste setor seria o fato de se tratar de uma indústria muito competitiva, sendo vital a atualização dos produtos. Dentre as empresas que compõem este setor se destaca as montadoras de veículos que investiam em 2011 1,39\% da sua receita operacional em P\&D e 2,79\% em atividades inovativas, enquanto no mesmo período as indústrias de transformação investiam $0,72 \% \mathrm{em}$ P\&D e 2,46\% em atividades inovativas. Isso significa que estas empresas vêm realizando um esforço inovativo acima do realizado em outras indústrias.

Na tabela 2 são apresentados os números de empresas participantes (empresas que declararam ter usufruído dos incentivos fiscais) por região. Mesmo com um crescimento percentual de empresas participantes da Lei do Bem muito maior que das regiões sul e sudeste no comparativo dos anos de 2006 e 2014, juntas, as regiões norte, nordeste e centro-oeste têm, em 2014, 7,55\% do total de empresas beneficiadas. O MCTIC (2015) afirma que tem feito esforços juntamente com outras instituições do setor público e privado, para sensibilizar e mobilizar junto ao setor empresarial das referidas regiões, procurando difundir e estimular a cultura da inovação e os benefícios da Lei do Bem. 
Tabela 2 - Número de empresas participantes por região no Brasil

\begin{tabular}{rr|rrrrrr}
\hline Regiões & Norte & Nordeste & Centro-Oeste & Sudeste & Sul & Total \\
\hline 2006 & 1 & 3 & 1 & 73 & 52 & $\mathbf{1 3 0}$ \\
2007 & 3 & 16 & 1 & 192 & 121 & $\mathbf{3 3 3}$ \\
2008 & 9 & 27 & 1 & 311 & 204 & $\mathbf{5 5 2}$ \\
2009 & 7 & 24 & 8 & 366 & 230 & $\mathbf{6 3 5}$ \\
2010 & 9 & 30 & 8 & 502 & 326 & $\mathbf{8 7 5}$ \\
2011 & 16 & 37 & 18 & 567 & 324 & $\mathbf{9 6 2}$ \\
2012 & 18 & 41 & 17 & 634 & 332 & $\mathbf{1 0 4 2}$ \\
2013 & 19 & 44 & 22 & 711 & 362 & $\mathbf{1 1 5 8}$ \\
2014 & 26 & 43 & 22 & 727 & 388 & $\mathbf{1 2 0 6}$ \\
\hline
\end{tabular}

Fonte: (MCTIC/ SETEC, 2015, p. 14)

No gráfico 1 observam-se os investimentos realizados pelas empresas em $\mathrm{P} \& \mathrm{D}$, segregando estes valores em despesas de custeio (despesas com salários, materiais e serviços de consumo, por exemplo) e despesas de capital (investimento para aumento do patrimônio da empresa, como compra de máquinas e equipamentos).

Gráfico 1 - Investimentos realizados pelas empresas em P\&D

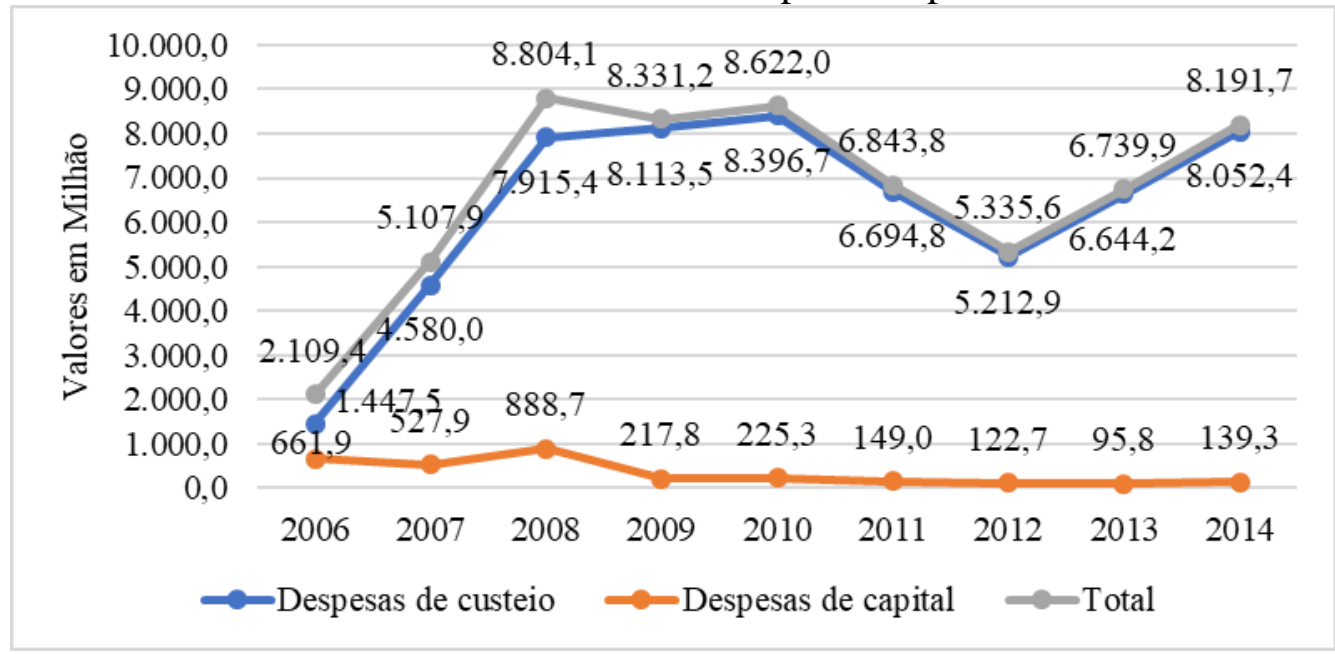

Fonte: Elaborado pelos autores com base em informações do MCTIC (2018)

Percebe-se que após o ano de 2008 os investimentos em P\&D apresentaram uma retração, mais acentuada no ano de 2012. De acordo com o relatório do MCTIC (2013), esta queda deve-se aos efeitos colaterais advindos do cenário macroeconômico dos três anos anteriores (2009 a 2011), que desestimulou ou inibiu novos investimentos em P\&D. Comparando os investimentos em $\mathrm{P} \& \mathrm{D}$ em relação ao número de participantes, percebe-se que a média dos investimentos foi reduzindo ao longo do período (vide tabela 3). Pode-se deduzir que não houve um aumento em investimentos em P\&D e sim um aumento de empresas participantes que elevou os valores de investimento em $\mathrm{P} \& \mathrm{D}$. Como não há um histórico das atividades de P\&D das empresas, não é possível afirmar se elas já possuíam ou não atividades de pesquisa tecnológica antes de aderirem à Lei do Bem. Mesmo não constando nenhuma tabela que faça o comparativo de investimentos em relação ao número de empresas declaradas, consta no relatório a seguinte observação no relatório do ano base 2013 que nos faz entender que esta análise é feita pelo ministério (MCTIC/ SETEC, 2013, p. 14): "apesar do crescimento do número de empresas participantes da Lei do Bem no ano-base de 2013, em relação ao anobase 2012, em contrapartida, houve, uma redução no valor dos investimentos (valor bruto) aplicados em P, D\&I, na proporção de $25 \%$ ". 


\begin{tabular}{c|c|c|c}
\multicolumn{5}{c}{ Tabela 3 - Média dos investimentos em P\&D } \\
\hline Ano & $\begin{array}{c}\text { Empresas } \\
\text { Participantes }\end{array}$ & $\begin{array}{c}\text { Investimento em P\&D } \\
\text { (em milhões) }\end{array}$ & $\begin{array}{c}\text { Média } \\
\text { Investimento }\end{array}$ \\
\hline $\mathbf{2 0 0 6}$ & 130 & $2.109,4$ & 16,23 \\
$\mathbf{2 0 0 7}$ & 333 & $5.107,9$ & 15,34 \\
$\mathbf{2 0 0 8}$ & 552 & $8.804,1$ & 15,95 \\
$\mathbf{2 0 0 9}$ & 635 & $8.331,2$ & 13,12 \\
$\mathbf{2 0 1 0}$ & 875 & $8.622,0$ & 9,85 \\
$\mathbf{2 0 1 1}$ & 962 & $6.843,8$ & 7,11 \\
$\mathbf{2 0 1 2}$ & 1042 & $5.335,6$ & 5,12 \\
$\mathbf{2 0 1 3}$ & 1158 & $6.739,9$ & 5,82 \\
$\mathbf{2 0 1 4}$ & 1206 & $8.191,7$ & 6,79 \\
\hline
\end{tabular}

Fonte: Elaborado pelos autores com base em informações do MCTIC (2018)

$\mathrm{Na}$ tabela 4 tem-se o valor total da renúncia fiscal segregada por ano e região. A maior parte destes incentivos provém da redução da base de cálculo do IR e da CSLL, que são as exclusões de até $60 \%$ dos gastos considerados como despesas operacionais realizados com $\mathrm{P} \& \mathrm{D}$, despesas com pesquisadores com dedicação exclusiva à $\mathrm{P} \& \mathrm{D}$, gastos com marcas $\mathrm{e}$ patentes e com dispêndios efetivados com projetos de pesquisa científica executados por ICT - Instituição Científica e Tecnológica. Esta renúncia pode variar de $20 \%$ a $34 \%$ dos gastos de P\&D realizados pelas empresas no país, podendo ser próprios ou contratados, de forma complementar, junto a empresas optantes do Simples Nacional, consultores independentes, universidades e instituições de pesquisa, desde que o risco e a responsabilidade de gestão e controle sejam realizados pelas empresas beneficiárias da Lei do Bem.

Tabela 4 - Renúncia fiscal por região

\begin{tabular}{r|r|r|r|r|r|r}
\hline \multicolumn{1}{c|}{ Região } & \multicolumn{1}{c|}{ Sudeste } & \multicolumn{1}{c|}{ Sul } & $\begin{array}{c}\text { Centro- } \\
\text { Oeste }\end{array}$ & \multicolumn{1}{c}{ Norte } & Nordeste & \multicolumn{1}{c}{ Total } \\
\hline 2006 & $165.344,90$ & $51.925,25$ & - & $1.283,25$ & $10.432,01$ & $\mathbf{2 2 8 . 9 8 5 , 4 1}$ \\
2007 & $718.888,77$ & $128.157,70$ & $2.603,58$ & $2.947,26$ & $31.297,43$ & $\mathbf{8 8 3 . 8 9 4 , 7 4}$ \\
2008 & $1.339 .267,08$ & $164.165,17$ & $5.364,38$ & $39.132,19$ & $34.784,03$ & $\mathbf{1 . 5 8 2 . 7 1 2 , 8 5}$ \\
2009 & $1.180 .074,80$ & $143.120,37$ & $8.874,00$ & $20.318,79$ & $30.370,01$ & $\mathbf{1 . 3 8 2 . 7 5 7 , 9 7}$ \\
2010 & $1.453 .147,65$ & $205.624,33$ & $6.204,56$ & $22.685,34$ & $39.476,92$ & $\mathbf{1 . 7 2 7 . 1 3 8 , 8 0}$ \\
2011 & $1.119 .445,64$ & $250.316,30$ & $8.732,47$ & $5.338,32$ & $26.151,12$ & $\mathbf{1 . 4 0 9 . 9 8 3 , 8 5}$ \\
2012 & $775.160,80$ & $199.974,43$ & $6.833,30$ & $42.296,41$ & $23.933,33$ & $\mathbf{1 . 0 4 8 . 1 9 8 , 2 7}$ \\
2013 & $1.180 .601,25$ & $267.475,27$ & $18.337,78$ & $78.665,48$ & $38.261,39$ & $\mathbf{1 . 5 8 3 . 3 4 1 , 1 7}$ \\
2014 & $1.317 .461,26$ & $251.893,49$ & $14.170,96$ & $79.120,19$ & $49.270,45$ & $\mathbf{1 . 7 1 1 . 9 1 6 , 3 5}$ \\
Total região & $\mathbf{9 . 2 4 9 . 3 9 2 , 1 5}$ & $\mathbf{1 . 6 6 2 . 6 5 2 , 3 1}$ & $\mathbf{7 1 . 1 2 1 , 0 3}$ & $\mathbf{2 9 1 . 7 8 7 , 2 3}$ & $\mathbf{2 8 3 . 9 7 6 , 6 9}$ & $\mathbf{1 1 . 5 5 8 . 9 2 9 , 4 1}$ \\
\hline
\end{tabular}

Fonte: Elaborado pelos autores com base em informações do MCTIC (2018)

As oscilações dos valores de renúncia fiscal podem ser explicadas pelo fato do incentivo ser concedido com base nos valores de P\&D investidos pelas empresas. No gráfico 2 foi feita uma comparação entre os valores da renúncia fiscal e dos investimentos em P\&D e percebe-se que os valores seguem a mesma tendência. 
Gráfico 2 - Comparação renúncia fiscal vs investimento em P\&D

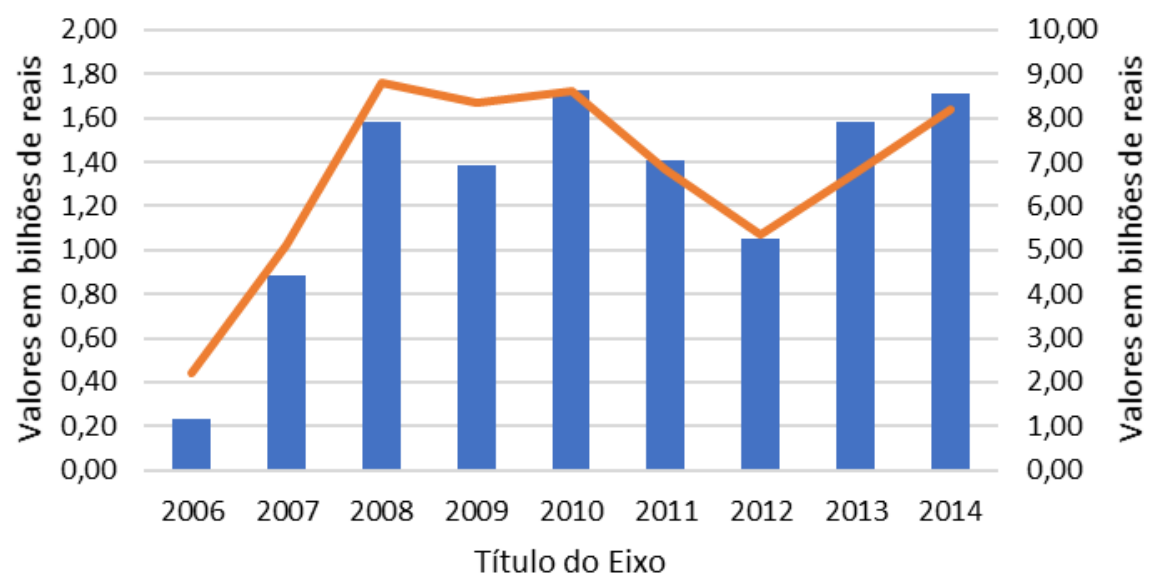

Total Renúncia fiscal $\quad$ Total investimento em P\&D

Fonte: Elaborado pelos autores com base em informações do MCTIC (2018)

Na tabela 5 observa-se uma relação entre investimento das empresas em P\&D, renúncia fiscal e PIB. O MCTIC deduz o incentivo concedido aos investimentos em P\&D para encontrar o valor real desembolsado pelas empresas em pesquisa e desenvolvimento e compara este montante em termos percentuais com o PIB. O MCTIC (2015) tinha como meta alcançar o percentual de $1,8 \%$ do PIB Brasil em investimentos em $\mathrm{P} \& \mathrm{D}$, porém o percentual atingido das empresas recomentadas foi $0,15 \%$. O MCTIC (2015) destaca que o investimento em pesquisa e desenvolvimento no setor empresarial brasileiro é muito maior do que os números apresentados no relatório. Isso porque apenas um número reduzido das empresas que mais investem em inovação no país (entre $15 \%$ e $20 \%$ ) está participando da Lei do Bem. Outro ponto ressaltado é que da meta de 1,8\% do PIB Brasil, a parcela correspondente à participação do setor privado era de 0,9\% (MCTIC/ SETEC, 2013).

Tabela 5 - Investimentos das empresas nas áreas de P\&D em relação ao PIB Brasil

\begin{tabular}{c|c|c|c|c|c|c}
\hline Ano-Base & $\begin{array}{c}\text { Investimento } \\
(\mathbf{A}) \\
(*)\end{array}$ & $\begin{array}{c}\text { Renúncia } \\
\text { Fiscal Total } \\
(\mathbf{B})\end{array}$ & $\begin{array}{c}\text { Investimento - } \\
\text { Renúncia Fiscal } \\
(\mathbf{A - B})\end{array}$ & $\begin{array}{c}\mathbf{P I B} \\
\mathbf{( C )} \\
(* *)\end{array}$ & $\begin{array}{c}(\boldsymbol{\%}) \\
(\mathbf{A} / \mathbf{C})\end{array}$ & $\begin{array}{c}(\boldsymbol{\%}) \\
(\mathbf{A - B}) / \mathbf{C})\end{array}$ \\
\hline 2006 & 2,19 & 0,23 & 1,96 & $2.433,00$ & 0,09 & 0,08 \\
2007 & 5,14 & 0,88 & 4,26 & $2.558,80$ & 0,20 & 0,17 \\
2008 & 8,80 & 1,58 & 7,22 & $2.889,70$ & 0,30 & 0,25 \\
2009 & 8,33 & 1,38 & 6,95 & $3.143,00$ & 0,27 & 0,22 \\
2010 & 8,62 & 1,73 & 6,89 & $3.675,00$ & 0,23 & 0,19 \\
2011 & 6,84 & 1,41 & 5,43 & $4.143,00$ & 0,17 & 0,13 \\
2012 & 5,34 & 1,05 & 4,29 & $4.403,00$ & 0,12 & 0,10 \\
2013 & 6,74 & 1,59 & 5,15 & $4.840,00$ & 0,14 & 0,11 \\
2014 & 8,19 & 1,71 & 6,48 & $5.521,00$ & 0,15 & 0,12 \\
\hline
\end{tabular}

(*) Refere-se ao investimento recomendado para cálculo dos incentivos fiscais adicionais concedidos pela Lei do Bem. Valores revisados e corrigidos. (**) Refere-se a dados do IBGE.

Fonte: (MCTIC/ SETEC, 2015, p. 21)

Os relatórios de 2013 e 2014 apresentaram informações relevantes que não constam nos demais relatórios, sendo elas o número de pesquisadores contratados com dedicação exclusiva e uma comparação entre o investimento e receita líquida das empresas incentivadas. Na tabela 6 observa-se uma queda na quantidade de pesquisadores contratados pelas empresas privadas 
para realizar exclusivamente atividades de pesquisa e desenvolvimento, não sendo computados os pesquisadores classificados na categoria de "tempo parcial".

Tabela 6 - Indicador estratégico sobre pesquisadores exclusivos em P\&D

\begin{tabular}{c|c|c|c|c|c|c|c}
\hline \multirow{2}{*}{ Ano-Base } & \multicolumn{7}{|c}{$\mathbf{N}^{\circ}$ de Pesquisadores Contratados - dedicação exclusiva } \\
\cline { 2 - 8 } & Doutores & Mestres & Pós-Graduados & Graduados & Tecnólogo & $\begin{array}{c}\text { Técnico } \\
\text { Nível Médio }\end{array}$ & Total \\
\hline 2010 & 609 & 1.662 & 5.817 & 15.143 & 568 & 5.199 & 28.998 \\
2011 & 614 & 1.627 & 5.218 & 15.279 & 517 & 4.485 & 27.740 \\
2012 & 640 & 1.538 & 5.369 & 12.245 & 513 & 3.938 & 24.243 \\
2013 & 697 & 1.630 & 2.155 & 13.219 & 1.035 & 5.323 & 24.059 \\
2014 & 484 & 1.077 & 2.094 & 12.660 & 372 & 3.686 & 20.373 \\
\hline
\end{tabular}

Fonte: (MCTIC/ SETEC, 2015, p. 25)

Para Archila (2015), o baixo número de pesquisadores contratados por empresas privadas é uma das maiores evidências sobre a modesta participação das empresas brasileiras no processo de inovação, dificultando também a interação universidade-empresa. Uma das possíveis causas da redução do número de pesquisadores contratados pelas empresas privadas seja o fato de que outras atividades inovativas, como aquisição de máquinas, softwares e equipamentos e treinamento, serem consideradas mais relevantes (ARCHILA, 2015). A autora ainda afirma que, de acordo com a pesquisa realizada pelo IBGE em 2014, apenas $5,76 \%$ das "empresas inovadoras do país realizaram atividades internas de P\&D e genuinamente usam essas atividades como estratégia sistemática para desenvolver novos produtos e processos" (ARCHILA, 2015, p. 6; IBGE, 2016).

Na tabela 7 é apresentada a comparação entre os investimentos líquidos em atividades de inovação das empresas na Lei do Bem e a receita líquida de vendas dos anos de 2010 a 2014. Observa-se uma queda nos investimentos em P\&D mesmo com o crescimento de empresas participantes. A redução nos investimentos também foi observada na tabela 3 quando é feita a análise da média de investimento por empresa. É possível que esta retração anual nos investimentos em $\mathrm{P} \& \mathrm{D}$ seja fruto das sucessivas instabilidades no cenário macroeconômico que o país vem enfrentando(MCTIC/ SETEC, 2015).

Tabela 7 - Indicador estratégico de resultados dos investimentos $v s$ receita líquida

\begin{tabular}{c|c|c|c}
\hline \multirow{2}{*}{ Ano-Base } & \multicolumn{3}{|c}{ Indicadores } \\
\cline { 2 - 4 } & $\begin{array}{c}\text { Investimento (*) } \\
(\mathbf{A})\end{array}$ & $\begin{array}{c}\text { Receita Líq. } \\
(* *) \\
(\mathbf{B})\end{array}$ & $\begin{array}{c}(\%) \\
(\mathbf{A} / \mathbf{B})\end{array}$ \\
\hline 2010 & 8,62 & 834,2 & 1,03 \\
2011 & 6,84 & 1170 & 0,58 \\
2012 & 5,34 & 1015 & 0,53 \\
2013 & 6,74 & 1146 & 0,59 \\
2014 & 8,19 & 1671 & 0,49 \\
\hline
\end{tabular}

(*) Refere-se ao investimento recomendado para cálculo dos incentivos fiscais concedidos pela Lei do Bem. (**) Refere-se ao total da receita líquida de vendas declarada pela empresa Fonte: (MCTIC/ SETEC, 2015, p. 27) 
Observa-se que em nenhum dos relatórios publicados pelo MCTIC se traz informações sobre metas a serem cumpridas pelas empresas incentivadas nem a vinculação de cumprimento destas para continuar a usufruir do benefício.

Os relatórios limitam-se a trazer, no que tange a resultados esperados do incentivo, informações relacionadas aos investimentos em P\&D. Contudo a análise do valor total de investimento em $P \& D$ não demonstra a realidade: dividindo-se o número de empresas participantes pelo valor total de $\mathrm{P} \& \mathrm{D}$ investido, observa-se que o valor de investimento não aumentou. $\mathrm{O}$ valor total apresentou aumento pelo fato de se terem ouras empresas participantes.

Os resultados dos investimentos em pesquisa e desenvolvimento não são medidos pelo MCTIC, tais como aumento de registro de marcas e patentes, de contratações de pesquisadores, de recebimento de royalties de transferência de tecnologia versus PIB, sem, também, se considerar o aumento do número de empresas beneficiadas, dentre outros.

Ao comparar o modelo brasileiro com o Sul Coreano, que tem inspirado os países latino americanos devido ao seu sucesso, percebe-se que esta última possuía metas que deveriam ser cumpridas pelas empresas incentivadas para poderem continuar a usufruir dos benefícios (DIAS, 2008; NELSON; WINTER, 2005).

\section{Conclusão}

Este trabalho analisou o modelo de avaliação governamental da Lei do Bem e as informações contidas nos relatórios do MCTIC, bem como a forma que avalia os retornos dos incentivos concedidos. Percebe-se que a avaliação do MCTIC é superficial e não apresenta efetivamente o cumprimento do objetivo do incentivo, que é incentivar o desenvolvimento tecnológico. Há uma grande preocupação do MCTIC em ter um maior volume no investimento em P\&D, mas o investimento por si só não gera desenvolvimento tecnológico. Precisa ser eficaz e gerar frutos como o aumento de registro de patentes e marcas, de contratações de pesquisadores, de royalties de transferência de tecnologia, dentre outras. Nos relatórios não há este tipo de informação. O MCTIC afirma que não existe uma meta de patentes, produtos e processos, receitas das empresas e de contratação de pesquisadores. O investimento somente se justificaria se gerasse ganhos reais para as empresas e para o país, que poderiam ser mensurados nesses indicadores antes comentados, por exemplo.

Os relatórios apresentam algumas informações de difícil leitura e entendimento quando traçada uma comparação entre os relatórios. Como exemplo deste ponto, pode-se citar o número de pesquisadores apresentado nos relatórios de 2013 e 2014. Outras informações começaram a ser apresentadas a partir do relatório de 2013, porém não foram apresentados os dados dos anos anteriores para comparação. Como exemplo, tem-se as informações do número de pesquisadores contratados com dedicação exclusiva e uma comparação entre o investimento e receita líquida das empresas incentivadas.

Por fim, o último relatório da Lei do Bem publicado pelo MCTIC refere-se ao ano de 2014. É necessária a divulgação tempestiva de dados atualizados para acompanhamento dos retornos dos incentivos fiscais concedidos.

Precisa-se que o governo gerencie melhor os retornos gerados pelas empresas incentivadas e cobre delas a efetiva promoção do desenvolvimento tecnológico do país. As empresas que apenas usufruem do incentivo, reduzindo os seus custos e tributos, mas não promovendo, de fato, o desenvolvimento tecnológico, devem ter seus benefícios negados. Os relatórios do MCTIC devem ser tempestivos e os controles devem primar pela apresentação dos retornos dos investimentos em P\&D. Somente $o$ aumento dos investimentos não faz o desenvolvimento tecnológico acontecer. É preciso que este investimento seja efetivo. 
Somente com o aumento de registros de patentes e de pesquisadores inseridos nas empresas, dentre outros indicadores, que o investimento em P\&D pode trazer e almejar alcançar melhores índices de inovação para o Brasil. 


\section{REFERÊNCIAS}

ALMEIDA, F. C. R. DE. Uma abordagem estruturada da renúncia de receita pública federal. Revista do TCU, n. 84, p. 19-62, 2000.

ARAÚJO, B. C. Incentivos fiscais à pesquisa e desenvolvimento e custos de inovação no Brasil. Radar: Tecnologia, Produção e Comércio Exterior, v. 8, p. 3-11, 2010.

ARAÚJO, C. A. Bibliometria: evolução histórica e questões atuais. Em questão, v. 12, n. 1, 2006.

ARAÚJO, C. A. Políticas de apoio à inovação no Brasil: uma análise de sua evolução recente. Brasília: $\quad$ IPEA, 2012. Disponível em: $<$ http://www.ipea.gov.br/portal/index.php?option=com_content\&view=article\&id=15200>. Acesso em: 28 jun. 2017.

ARCHILA, D. L. C. Condicionantes do potencial de exploração comercial da patente da Instituição de Ciência e Tecnologia (ICT) brasileira. Congresso Latino-Iberoamericano de Gestão da Tecnologia. Anais...2015

AUDRETSCH, D. B. et al. The economics of science and technology. The Journal of Technology Transfer, v. 27, n. 2, p. 155-203, 2002.

BRASIL. Lei 10.973 de 2 de dezembro de 2004. Dispõe sobre incentivos à inovação e à pesquisa científica e tecnológica no ambiente produtivo e dá outras providências. Brasília. 2004.

BRASIL. Decreto 5.798 de 7 de junho de 2006. Regulamenta os incentivos físcais às atividades de pesquisa tecnológica e desenvolvimento de inovação tecnológica, de que tratam os arts. 17 a 26 da Lei no 11.196, de 21 de novembro de 2005. 2006.

CALZOLAIO, A. E.; DATHEIN, R. Políticas Fiscais de Incentivo à Inovação: uma avaliação da Lei do Bem. Porto Alegre: Anpec Sul, 2012.

CASTRO, B. H. R. DE; BARROS, D. C.; VAZ, L. F. H. Panorama da engenharia automotiva no Brasil: inovação e o apoio do BNDES. BNDES Setorial, Rio de Janeiro, n. 39, p. 155196, 2014.

CHIANG, S.; LEE, P.; ANANDARAJAN, A. The effect of R\&D tax credit on innovation: A life cycle analysis. Innovation-management policy \& practice, v. 14, n. 4, p. 510-523, dez. 2012.

CONCEIÇÃO, O. A. C. A centralidade do conceito de inovação tecnológica no processo de mudança estrutural. Ensaios FEE, v. 21, n. 2, p. 58-76, 2000.

DIAS, R. O Brasil e a experiência Sul-Coreana: um rumo alternativo? Redes, v. 14, n. 28, p. 195-219, 2008.

FILIPPIN, F. Estado e Desenvolvimento: a indústria de semicondutores no Brasil. Mestrado em Economia—Campinas, SP: Universidade Estadual de Campinas, 2016. 
FORMIGONI, H. A influência dos incentivos fiscais sobre a estrutura de capital e a rentabilidade das companhias abertas brasileiras não financeiras. Doutorado em Ciências Contábeis-São Paulo: Universidade de São Paulo, 2008.

GALARRAGA, I.; ABADIE, L. M.; KALLBEKKEN, S. Designing incentive schemes for promoting energy-efficient appliances: A new methodology and a case study for Spain. Energy Policy, v. 90, p. 24-36, mar. 2016.

GODOY, A. S. Introdução à pesquisa qualitativa e suas possibilidades. Revista de administração de empresas, v. 35, n. 2, p. 57-63, 1995.

HOLANDA, F. C. S. DE; PIRES, M. DE M. Escala de valores: proposta de construção de um indicador de análise de inovação tecnológica. Revista Inova Ciência \& Tecnologia/Innovative Science \& Technology Journal, v. 1, n. 1, p. 42-53, 2015.

IBGE. Tabela 1.1.1 - Variáveis selecionadas das empresas, segundo as atividades da indústria, do setor de eletricidade e gás e dos serviços selecionados - Brasil - período 2012-2014.

Disponível

em: $<$ http://www.pintec.ibge.gov.br/index.php?option=com_content\&view=category\&layout=blo g\&id=30\&Itemid=46>. Acesso em: 8 nov. 2017.

INVENTTA. Análise do uso dos Incentivos Fiscais à Inovação em 2013. Disponível em: $<$ http://brasil.abgi-group.com/radar-inovacao/artigos-estudos/analise-lei-do-bem-2013/>. Acesso em: 6 nov. 2017.

LOKSHIN, B.; MOHNEN, P. How effective are level-based R\&D tax credits? Evidence from the Netherlands. Applied Economics, v. 44, n. 12, p. 1527-1538, abr. 2012.

LOPES, I. F.; BEUREN, I. M. Evidenciação da Inovação no Relatório da Administração: uma análise na perspectiva da Lei do Bem (Lei N ${ }^{\circ}$. 11.196/2005). Perspectivas em Gestão \& Conhecimento, v. 6, n. 1, p. 109-127, 2016.

MARQUES, B. A.; LEAL, D. Contribuição da lei do bem para o planejamento tributário de uma unidade empresarial e a percepção dos contadores do estado do espírito santo sobre incentivos fiscais e planejamento tributário. Revista Ambiente Contabil, v. 8, n. 2, p. 40-58, 2016.

MCTIC. Incentivos ao Desenvolvimento. Disponível em: <http://www.mctic.gov.br/mctic/opencms/tecnologia/incentivo_desenvolvimento/lei_bem/_be m/Lei_do_Bem.html>.Acesso em: 4 nov. 2017.

MCTIC/ SETEC. Relatório anual da utilização dos incentivos fiscais: ano base 2012. Brasília: [s.n.]. Disponível em: <http://www.mctic.gov.br/mctic/export/sites/institucional/tecnologia/incentivo_desenvolvime nto/lei_bem/arquivos/Relatorio-Anual-Lei-11196-05-Ano-Base-2012.pdf>.

MCTIC/ SETEC. Relatório anual de atividades de P\&D (retificado) 2014. Brasília: [s.n.]. Disponível em: <http://www.mctic.gov.br/mctic/export/sites/institucional/tecnologia/incentivo_desenvolvime nto/lei_bem/arquivos/Relatorio-Anual-Lei-11196-05-Ano-Base-2014-Retificado.pdf>. 
MDIC. PADIS. Disponível em: <http://www.mdic.gov.br/index.php/noticias/105assuntos/competitividade-industrial/474-regime-de-autopecas-nao-produzidas-ex-tarifariosde-autopecas-10>. Acesso em: 16 mar. 2018.

MELO, P. R. DE S.; RIOS, E. C. S. D.; GUTIERREZ, R. M. V. Componentes eletrônicos: perspectivas para o Brasil. BNDES Setorial, Rio de Janeiro, n. 13, p. 3-63, 2001.

MDIC. O que é PPB? Disponível em: <http://www.mdic.gov.br/competitividadeindustrial/ppb/o-que-e-ppb>. Acesso em: 9 ago. 2017.

NELSON, R. R.; WINTER, S. G. Uma teoria evolucionária da mudança econômica. Campinas, SP: Editora da UNICAMP, 2005.

NIOSI, J. et al. National systems of innovation: in search of a workable concept. Technology in society, v. 15, n. 2, p. 207-227, 1993.

OECD (ED.). Manual de Oslo: Diretrizes para coleta e interpretação de dados sobre inovação. Traducao FINEP. $3^{\mathrm{a}}$ ed. Oslo: Organização para Cooperação e Desenvolvimento Econômico, 2004.

OECD. Manual de Frascati 2002. Medição de atividades científicas e tecnológicas. Tipo de metodologia proposta para levantamos sobre pesquisa e desenvolvimento experimental. São Paulo: F-Iniciativas, 2013.

PRATA, Á. T. Prefácio. In: Guia da Lei do Bem: o que é inovação para a Lei do Bem? São Paulo: ANPEI, 2017.

RUMINA, U. A.; BALANDINA, A. S.; BANNOVA, K. A. Evaluating the Effectiveness of Tax Incentives in Order to Create a Modern Tax Mechanism Innovation Development. Procedia - Social and Behavioral Sciences, v. 166, p. 156-160, jan. 2015.

SANTOS, I. E. Manual de métodos e técnicas de pesquisa científica. 9. ed. Niterói: Impetus, 2012.

SCHUMPETER, J. A. Teoria do Desenvolvimento Econômico - Uma Investigação sobre Lucros, Capital, Crédito, Juro e Ciclo Econômico. São Paulo: Nova Cultural, 1997.

SECCHI, L. Políticas públicas: conceitos, esquemas de análise, casos práticos. $2^{\text {a }}$ ed. São Paulo: Cengage Learning, 2013.

VIEIRA, A. C. P. et al. TRIPLE HELIX E INOVAÇÃO: A RELAÇÃO COM OS VALES DA UVA GOETHE. 2015.

VIOTTI, E. B. Brazil: From S\&T to innovation policy? The evolution and the challenges facing Brazilian policies for science, technology and innovation. Georgia Institute of Technology, 2008Disponível em: <https://smartech.gatech.edu/handle/1853/36899>. Acesso em: 2 jul. 2017

ZITTEI, M. V. M. et al. Lei do bem: o incentivo da inovação tecnológica como aumento da competitividade global do Brasil. Revista Gestão Inovação e Tecnologias, v. 6, n. 1, p. 2925-2943, 27 mar. 2016. 
ZUCOLOTO, G. F. Lei do Bem: impactos nas atividades de P\&D no Brasil. Radar: tecnologia, produção e comércio exterior, v. 6, p. 14-20, 2010. 